\title{
Jogo de RPG para o Desenvolvimento de Habilidades do Pensamento Computacional no Ensino Fundamental ${ }^{*}$
}

\author{
Placida Oliveira $^{1}$, Jonnhy Marques ${ }^{1}$, Simone Cavalheiro ${ }^{1}$, Luciana Foss ${ }^{1}$, \\ Renata Reiser ${ }^{1}$, Andre Du Bois ${ }^{1}$, Clause Piana ${ }^{1}$, Ana Rita Mazzini ${ }^{1}$ \\ ${ }^{1}$ Universidade Federal de Pelotas \\ Rua Gomes Carneiro, 1 - CEP 96010-610 - Pelotas - RS - Brasil \\ \{pgsdoliveira, jmmarques, simone.costa, lfoss\}@inf.ufpel.edu.br
}

\begin{abstract}
This work proposes a methodology for application of an educational role-playing game, aiming to integrate the mathematics teaching with the following concepts and techniques of Computational Thinking: data and processes abstractions, and pattern matching. A case study was developed and the results obtained give evidence that activities involving games are attractive and effective for students' learning.
\end{abstract}

Resumo. Este trabalho propõe uma metodologia para aplicação de um jogo educacional de RPG, com o objetivo de integrar o ensino de matemática com os seguintes conceitos e técnicas do Pensamento Computacional: abstração de dados e processos, e reconhecimento de padrões. Um estudo de caso foi desenvolvido e os resultados obtidos dão indícios de que a realização de atividades envolvendo jogos são atrativas e eficazes para o aprendizado dos alunos.

\section{Introdução}

Com a chegada da chamada era digital, também conhecida como era tecnológica, o conhecimento se tornou cada vez mais valorizado, trabalhos foram automatizados e o tempo foi otimizado. Transformações que ocorrem graças a esta era influenciam o mercado de trabalho, que se mostra mais competitivo a cada dia. Com isso, surge a busca por profissionais ágeis, criativos, inovadores e qualificados para trabalhar em diversos setores e áreas, geralmente envolvendo multidisciplinaridade e capacidade de trabalhar em equipe. A alta demanda por estes profissionais revela a falta de indivíduos preparados para atuar diante de tais avanços tecnológicos que estão cada vez mais acelerados. Surge então, a necessidade de capacitar desde a infância, pessoas que possam futuramente ser inseridas no mercado de trabalho com as habilidades necessárias para atuar nesta desafiadora era.

Diante desta realidade, o Pensamento Computacional (PC) surge como uma alternativa. Wing (2006) descreve-o como uma metodologia baseada nos fundamentos da Ciência da Computação para a resolução de problemas, tanto computacionais quanto das mais diversas áreas do conhecimento. Essa metodologia abrange uma série de técnicas usualmente empregadas por profissionais da área da Computação, tais como, decomposição, generalização, abstração, entre outras. Diante disso, o PC permite qualificar estes futuros profissionais, estimulando o desenvolvimento de competências que possam facilitar o trabalho conjunto e interdisciplinar.

\footnotetext{
*O presente trabalho foi realizado com apoio da Coordenação de Aperfeiçoamento de Pessoal de Nível Superior - Brasil (CAPES) - Código de Financiamento 001 e da PREC e PRPPG / UFPel.
} 
Diversas abordagens visam qualificar o processo de ensino e aprendizagem por meio do desenvolvimento de competências do PC. Entre elas, destaca-se a utilização de jogos educacionais [Junior et al. 2018, Melo et al. 2018], que são uma interessante ferramenta de apoio ao aprendizado, pois promovem a inserção do lúdico às disciplinas, tornando-as mais atrativas e desafiadoras aos estudantes [da Silva et al. 2014, Pires et al. 2018, Junior et al. 2018, Melo et al. 2018]. Em particular, alguns trabalhos integram [Cao et al. 2019, Costa et al. 2015, Clarke et al. 2016] o desenvolvimento e o uso de jogos do gênero RPG (role playing games) [Gygax and Arneson 1974] ao desenvolvimento de habilidades do PC. Caracterizados como jogos de representação de papéis, a cooperação e a criatividade são destacados como os principais elementos desse gênero [Grando and Tarouco 2008]. No caso dos RPGs de mesa, há um tabuleiro que descreve o cenário do jogo e um mestre que guia os jogadores ao longo da partida. Nos RPGs digitais, o jogo (cenários, regras, discussões) é parcialmente definido por um programa de computador.

Diferenciando-se de outras abordagens propostas, o presente trabalho apresenta uma metodologia para aplicação de um jogo de tabuleiro do gênero RPG [Bartz 2018], com o objetivo de integrar o ensino da unidade de conhecimento Números e Operações da matemática para as séries iniciais [MEC 2018] com conceitos e técnicas relacionados ao PC [Csizmadia et al. 2015, Ribeiro et al. 2017], em particular, a abstração e o reconhecimento de padrões. A abstração é um mecanismo que permite simplificar a realidade e representar os aspectos mais relevantes de um problema e sua solução, compreendendo abstrações de dados e de processos (pensamento algorítmico). A abstração de dados permite descrever as informações envolvidas na solução de um problema (dados de entrada e de saída). Já a abstração de processos possibilita definir os algoritmos que descrevem essa solução. O reconhecimento de padrões permite identificar padrões, similaridades e conexões entre problemas e soluções, explorando estas características. Além da proposta de aplicação, relata-se o resultado de um estudo de caso feito com alunos do quarto ano do ensino fundamental. A metodologia adotada foi a desplugada [Bell et al. 1999] de forma a maximizar a replicação da atividade na rede pública do município de Pelotas, no qual muitas escolas não possuem infraestrutura e recursos tecnológicos disponíveis para uma abordagem digital.

O artigo está organizado como segue. A seção 2 descreve a proposta metodológica da atividade Elementais RPG. Na seção 3 é feito um relato da aplicação e na seção 4 é realizada uma discussão dos resultados. A seção 5 apresenta as considerações finais.

\section{Atividade Elementais RPG}

Baseando-se na proposta de [Bartz 2018], a atividade Elementais RPG foi adaptada em 5 tarefas, descritas nas próximas subseções. Os planos de ensino, de aulas e as avaliações, assim como todos os materiais utilizados nas tarefas estão detalhados e disponibilizados no site do projeto ${ }^{1}$.

\subsection{Tarefa I: Introdução dos elementos}

Objetivo: introduzir os personagens do jogo Elementais RPG, relacionando-os com os elementos água, planta e fogo, bem como apontando sua forças e fraquezas.

\footnotetext{
${ }^{1}$ https://wp.ufpel.edu.br/pensamentocomputacional/pt/
} 
Metodologia: são apresentados três cartões com os personagens do jogo (veja Figura 1): o Tocha (do elemento fogo); o Marinho (do elemento água); e a Carnívora (do elemento planta). Em seguida, é exibido um desenho com três imagens (uma gota de água, uma árvore e uma fogueira): a primeira imagem refere-se à água, a segunda à planta e a terceira ao fogo. Após, faz-se o seguinte questionamento: "O que deve ser feito para apagar o fogo?" (levar à conclusão de que a água apaga o fogo); "E se colocarmos gravetos e folhas secas no fogo, o que aconteceria?" (levar à conclusão de que o fogo aumentará); "Como fazemos para a planta crescer?" (levar à conclusão de que se deve regar a planta, isto é, consumir água); e "O que aconteceria se a planta queimasse?" (levar à conclusão de que ela seria destruída). Deve ser feita a relação dos personagens (Marinho, Carnívora e o Tocha) com os três elementos (água, planta e fogo) e, a seguir, faz-se a seguinte pergunta aos alunos: "Vocês acham que se o Marinho atacasse o Tocha, ele venceria?" Deve-se levar os alunos à conclusão de que sim, o Marinho venceria, pois ele é do elemento água e este elemento ganha do elemento fogo, ao qual o Tocha pertence. Outros exemplos de confrontos devem ser dados para que os alunos entendam a proposta. Depois do encerramento dos exemplos e das possíveis dúvidas sanadas, o professor deve dividir os alunos em duplas e entregar a cada um 6 cartinhas com os personagens do jogo ( 2 cartas de cada personagem) e, então, explicar o funcionamento do jogo. $\mathrm{O}$ jogo consiste de uma série de 6 confrontos, onde, em cada confronto, os alunos escolhem suas cartas e jogam na mesa ao mesmo tempo. Com a ajuda do professor, eles analisam quem foi o vencedor do confronto e anotam o resultado. Ao final da batalha (série de confrontos), o vencedor será o aluno que obtiver o maior número de vitórias.
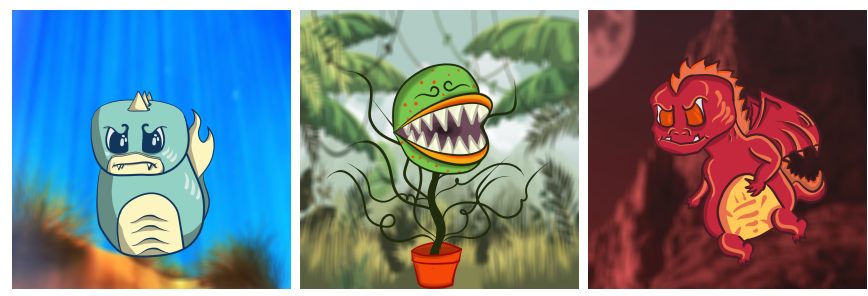

Figura 1. Personagens Marinho, Carnívora e Tocha. Fonte: [Bartz 2018]

Avaliação: são realizados alguns questionamentos como: qual o tipo de cada personagem e qual o resultado de um confronto entre dois personagens. Além disso, devem ser feitas simulações de diversos confrontos, onde os alunos escolhem o personagem mais adequado para vencer cada um deles. Em seguida, simula uma batalha, indicando ao fim de cada confronto o vencedor (se houver, caso não ocorra empate) e, o final, o vencedor da batalha, dado pelo jogador com o maior número de confrontos ganhos.

\subsection{Tarefa II: Relação de simetria}

Objetivo: trabalhar a noção de relações simétricas, além de fixar as características dos personagens já apresentados.

Metodologia: o professor começa exibindo cartões com os personagens do jogo e questiona os alunos sobre o nome de cada um. Diante disso, à medida que vão respondendo, os personagens vão sendo colados no quadro e o nome de cada um deve ser escrito abaixo do cartão. A seguir, o professor deve explicar que, em um confronto, se um personagem é mais forte do que seu adversário, este personagem ganharia a disputa, caso contrário ele 
perderia. Aqui é importante destacar a simetria entre as relações ganha (perde) e não perde (não ganha), isto é, se um personagem ganhou significa que ele não perdeu e vice-versa. Assim, devem ser realizadas simulações de confrontos entre dois personagens, dispostos conforme a Figura 2. Inicialmente, o professor pergunta para a turma se o personagem do lado esquerdo ganha ou não ganha do personagem do lado direito. Posteriormente, com os mesmos personagens, o professor questiona se o personagem do lado esquerdo perde ou não perde para o personagem da direita. Vários exemplos como esses são apresentados para que os alunos entendam que essas relações são simétricas.
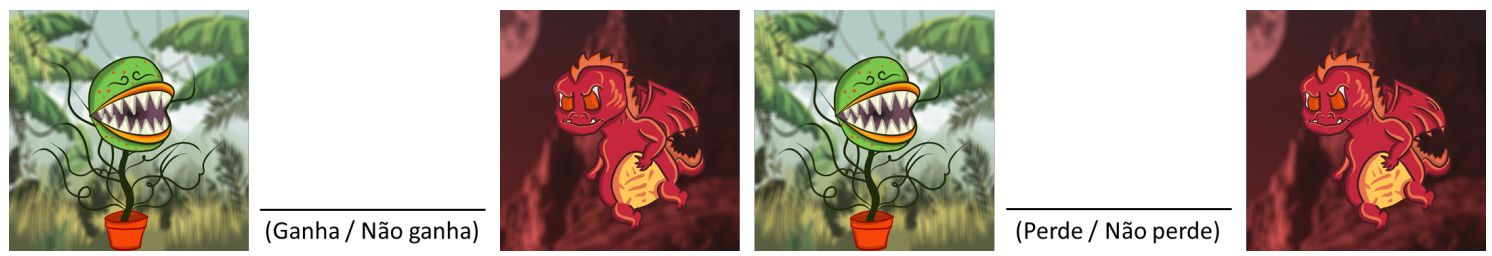

Figura 2. Disposição dos cartões para evidenciar as relações simétricas.

Avaliação: são realizadas novas simulações onde os alunos devem indicar se um personagem ganha/perde ou não ganha/não perde um confronto. Além disso, é verificada a compreensão da situação de empate entre os personagens, para verificar se houve o entendimento de que um personagem não ganha/não perde dele mesmo.

\subsection{Tarefa III: Dano e Vida}

Objetivo: adicionar duas novas informações aos confrontos do jogo Elementais RPG: dano e vida dos personagens.

Metodologia: inicia-se com o professor anunciando que o jogo terá novos personagens, pertencentes aos mesmos elementos já vistos, mas agora incluindo as informações de dano e vida nas descrições das cartas (Figura 3). Explica-se que nos confrontos devem ser consideradas duas novas informações que variam conforme o personagem escolhido: o valor do dano causado em um ataque, situado na parte inferior da carta, e o valor da vida do personagem, localizado na parte superior da carta. Em um confronto, o valor de dano de um personagem é subtraído da vida do seu adversário, e vice-versa. Para demonstrar esses conceitos, o professor deve fixar cartões de dois personagens no quadro e realizar vários exemplos de confrontos. Após, a turma deve ser dividida em duas equipes, onde cada uma recebe 6 cartões com personagens. As equipes disputarão uma série de 6 batalhas, onde cada batalha termina quando um dos personagens ficar sem vida. Em uma batalha, um componente de cada equipe se posiciona à frente com um personagem previamente escolhido e juntos fixam suas cartas no quadro. Uma batalha é realizada entre esses personagens e o vencedor ganha um ponto. As cartas selecionadas em uma batalha não voltam para o jogo. No final, a equipe vencedora será aquela que tiver mais pontos.

Avaliação: deve ser baseada na realização de várias batalhas, onde os alunos devem identificar: o número de vidas dos dois personagens após cada confronto; qual deles obteve o melhor desempenho e o porquê; quantos confrontos foram necessários para acabar uma batalha; e quem foi o vencedor da batalha.

\subsection{Tarefa IV: Dano, Vida e Força}

Objetivo: revelar todas as informações presentes nas cartas (conforme a Figura 4), introduzindo informações sobre força (quadro inferior das cartas), onde é possível observar 


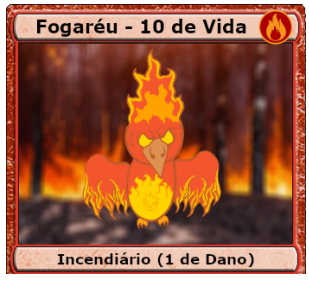

Figura 3. Personagem com atributos vida e dano. Fonte: Adaptada de [Bartz 2018]

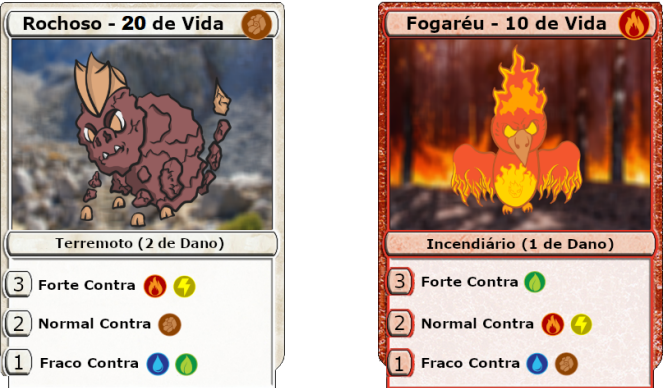

Figura 4. Personagens com atributos vida, dano e força. Fonte: [Bartz 2018]

contra quais elementos o personagem tem mais força.

Metodologia: inicia com o professor relembrando as informações das cartas do jogo já apresentadas. Em seguida, ele deve fixar no quadro o cartão do personagem Fogaréu (ilustrado na Figura 4) e explicar as informações que foram adicionadas. Deve introduzir também dois novos elementos: o elétrico e o pedra. Na parte superior da carta são mantidas as informações já conhecidas pelos alunos como o nome do personagem, número de vidas e o elemento ao qual ele pertence. No centro da carta está a informação do valor de dano que o personagem causa ao realizar um ataque. Por fim, na parte inferior da carta são mostradas as novas informações, relacionadas ao número de ataques que cada personagem realiza em um confronto contra um personagem de um determinado elemento. O número de ataques está divido em 3 níveis: forte, normal ou fraco. Essa informação é usada nos confrontos em conjunto com o dano. Por exemplo, o personagem Rochoso (Figura 4) tem um ataque com 2 de dano e, pelas informações de força, ele é forte contra um adversário de elemento fogo, tendo direito a 3 ataques, por confronto. Assim, em um confronto contra o Fogaréu, ele causaria um total de 6 danos, pois teria direito a 3 ataques com 2 danos cada. De forma análoga, personagens de nível normal ou fraco terão direito ao número de ataques por confronto conforme o indicado nas informações de força. Para reforçar a dinâmica dos confrontos, diversos exemplos de batalhas são apresentados, onde o ganhador é o personagem que conseguir zerar a vida de seu adversário primeiro. Devese anotar no início da batalha o valor da vida de cada personagem e ir subtraindo após cada confronto. Em seguida, a turma é dividida em 2 equipes e são entregues 9 cartões para cada equipe. É realizada uma série de 5 batalhas com a mesma dinâmica de jogo descrita na tarefa III, porém agora fazendo uso das informações de força nos confrontos.

Avaliação: deve ser baseada na simulação de confrontos em sequência, onde os alunos devem identificar o personagem que tem maior chance de vencer o confronto com base nas suas informações de dano, vida e força.

\subsection{Tarefa V: Batalhas no Tabuleiro}

Objetivo: apresentar o jogo na sua forma completa, adicionando o uso de tabuleiro e dados, além de cartas especiais que podem ser conquistadas durante o jogo.

Metodologia: inicia-se com a apresentação das cartas e do tabuleiro (Figura 5), explicando os papéis dos jogadores, os detalhes do tabuleiro e a dinâmica do jogo. Existem dois tipos de jogadores que irão batalhar uns contra os outros: os aventureiros e os mes- 


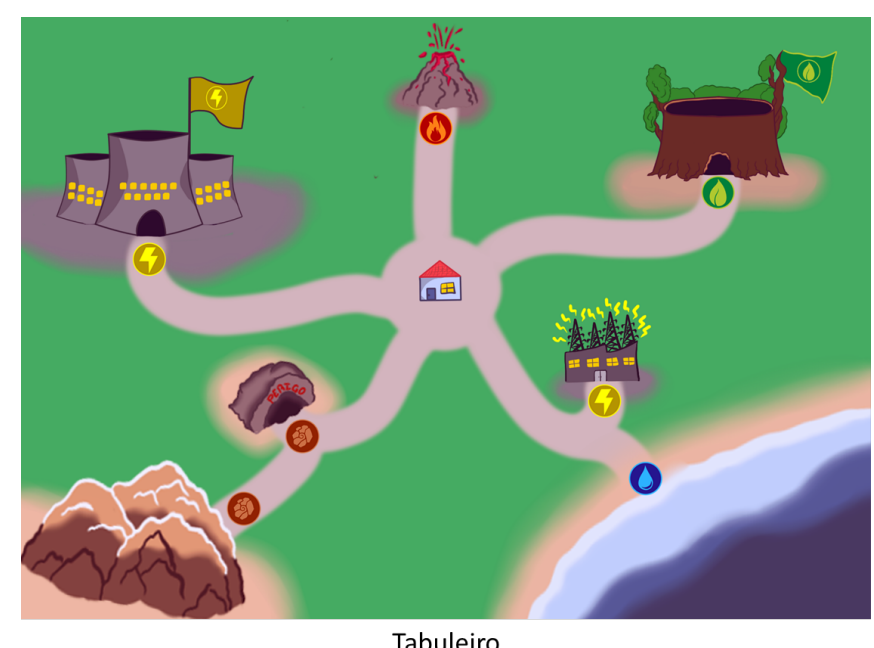

Tabuleiro
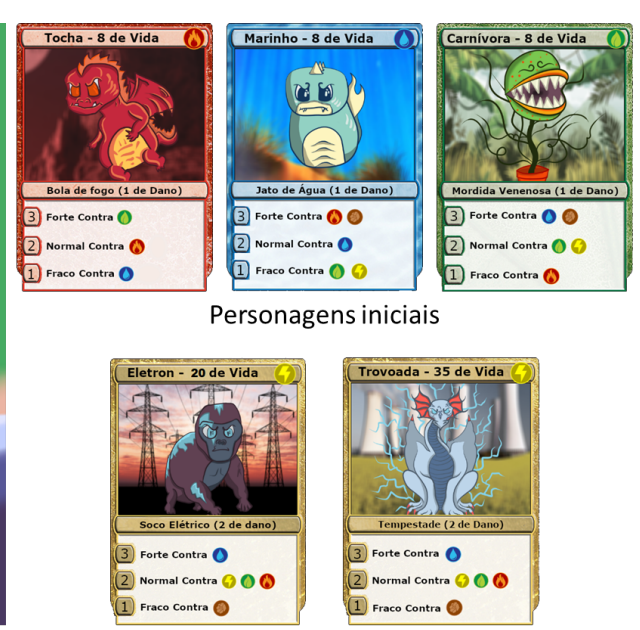

Exemplo de Mestre / Chefão

Figura 5. Exemplos de personagens e tabuleiro do jogo. Fonte: [Bartz 2018]

tres/chefões. Os mestres/chefões serão personagens com um valor de vida maior do que os personagens dos aventureiros (veja exemplos de mestres/chefões na Figura 5). O tabuleiro, ilustrado na Figura 5, representa um mapa com diferentes tipos de lugar: casinha de partida (centro do mapa), quadras e arenas (lugares demarcados por bandeiras). Em cada quadra/arena fica um mestre/chefão com um personagem do elemento indicado na entrada do local. Os aventureiros iniciam o jogo com as três cartas iniciais (Figura 5) e partem da casinha localizada no centro do tabuleiro. Os mestres/chefões são escolhidos e suas cartas são posicionadas nos respectivos lugares voltadas para baixo, ocultando o personagem. Os aventureiros devem percorrer os lugares do tabuleiro batalhando com os mestres/chefões. A escolha do caminho a ser percorrido é livre. A identidade do mestre/chefão permanece desconhecida até que os aventureiros entrem no local (apenas seu tipo é conhecido). Além disso, os aventureiros devem escolher com qual personagem vão iniciar a batalha antes de entrar na quadra/arena. Quando os aventureiros entram em um local, o mestre/chefão é revelado e o primeiro confronto se inicia. Os confrontos ocorrem em turnos, iniciando sempre com o ataque do aventureiro, seguido do contraataque do mestre/chefão. As vidas restantes de ambos os personagens são registradas a cada confronto. Esse valor é obtido de forma semelhante à descrita na tarefa anterior, porém adiciona-se mais um fator neste cálculo: antes de desferir seus ataques em cada confronto, tanto os aventureiros quanto os mestres/chefões devem jogar um dado, cujo resultado pode alterar o seu número de ataques naquele confronto. Caso o resultado do dado seja 1 ou 2, o personagem perde um ataque dos que teria direito; caso seja 3 ou 4, ele mantém o mesmo número de ataques; e caso resulte em 5 ou 6 , ele aumenta um ataque. Após cada confronto, se o personagem dos aventureiros tiver sua vida zerada, estes devem escolher outro personagem para continuar batalhando. A batalha termina quando todos os personagens dos aventureiros tiverem suas vidas zeradas ou quando as vidas zeradas forem as do mestre/chefão. No primeiro caso, os aventureiros saem do local derrotados e no segundo eles dominam a quadra/arena e ganham uma nova carta com o mesmo personagem do mestre/chefão vencido, porém com um valor de vida menor. Observe que uma estratégia de percorrer o tabuleiro começando pelas quadras proporciona aos aventureiros uma chance maior de sucesso, visto que no início seus personagens são mais fracos e à medida que dominam os lugares vão recebendo personagens mais fortes e de diferentes 
tipos de elementos. O jogo pode terminar no caso dos aventureiros terem: ou dominado todas as quadras/arenas do tabuleiro; ou decidido encerrar as batalhas. Pode-se dizer que os aventureiros obtiveram sucesso no jogo caso eles tenham dominado pelo menos uma arena. Neste caso, eles recebem como prêmio uma carta especial com um personagem do jogo. Após a apresentação do jogo, o professor divide a turma em trios e entrega o material a cada grupo: um tabuleiro, um dado e as três cartas iniciais do jogo. A seguir, pede para que cada aluno escolha um dos personagens iniciais e inicie o jogo selecionando uma arena/quadra como primeiro destino. A cada nova batalha, os aventureiros devem escolher três de seus personagens (distintos) para participar da disputa.

Avaliação: consiste em observar se os alunos conseguiram realizar todas as etapas do jogo e chegaram ao final com uma carta especial em mãos.

\section{Relato de Aplicação e Relações com o PC}

A atividade descrita na seção 2 foi aplicada a uma turma de 27 alunos do $4^{\circ}$ ano do Ensino Fundamental de uma escola da rede pública do município de Pelotas. Foram realizados encontros semanais de 1 hora de duração cada de setembro a dezembro de 2019. No primeiro, foi realizado um pré-teste com questões relacionadas às habilidades trabalhadas na atividade, o qual foi repetido no último encontro (pós-teste) ${ }^{2}$. Os alunos mostraram interesse em participar das atividades, principalmente daquelas que envolviam disputas em equipe. Além disso, os personagens das cartas também foram bastante apreciados. Com a motivação despertada pelas atividades, os alunos acabaram superando uma das principais dificuldades que foi encontrada: a realização de operações aritméticas.

As tarefas que compõem essa atividade se propõem a trabalhar alguns conceitos e habilidades do PC. Em todas as tarefas se faz uso de testes condicionais (estruturas de controle que fazem parte da habilidade do pensamento algorítmico) ao comparar os poderes dos personagens. Esses testes vão variando em complexidade conforme a evolução das tarefas. Inicialmente (tarefas I e II) o teste depende só do tipo do elemento dos personagens (uma comparação simples). Depois, o teste depende também de valores de dano e de vida, envolvendo a subtração (tarefa III). Na sequência, (tarefa IV) o teste inclui valores de força, envolvendo, além da subtração, a multiplicação. Por fim, na última etapa (tarefa V), adiciona-se o uso do dado, o que faz com que se utilizem mais de um teste condicional: o primeiro teste diz respeito ao número tirado no dado para selecionar um valor; e o segundo diz respeito a comparação das forças para definir o número de ataques. Outra habilidade trabalhada nesta atividade é o reconhecimento de padrões. O elemento de cada personagem define o padrão de ataques a ser realizado em cada confronto. $\mathrm{Na}$ tarefa II, para identificação das relações simétricas também se usou o reconhecimento de padrões. Além disso, na última tarefa usam-se padrões para diferenciar arenas de quadras. A abstração, tanto de dados quanto de processos, também se faz presente em todas as tarefas. As cartas dos personagens representam uma abstração para as suas características (seus atributos como número de vidas, danos e força). Além disso, os confrontos e batalhas constituem abstrações de processos, onde eles tem como entradas as cartas, definem sequências de ações e retornam um resultado (nas primeiras tarefas o resultado define o vencedor e nas demais consiste da vida restante dos personagens). Durante a aplicação

\footnotetext{
${ }^{2} \mathrm{O}$ pré/pós-teste corresponde as questões 4 a 8 disponível em https://drive.google.com/ file/d/1Jm0XUDknrUxnTpAwEoKE2iazuuKf7DlV/view.
} 
das tarefas, observou-se que os alunos não tiveram dificuldade com nenhum dos conceitos/habilidades do PC que foram abordados, com exceção do reconhecimento de padrões associado à identificação das relações de simetria. Neste caso, os alunos tiveram dificuldades de associar a relação de "ganhar" com "não perder".

\section{Resultados e Discussão}

A atividade foi desenvolvida em seis encontros. Cada tarefa compreendeu um encontro, com exceção da tarefa 3 que ocorreu em dois. Ao final de cada um dos cinco primeiro encontros, os alunos foram avaliados por meio de um teste escrito, com pontuação variando numa escala de 0 a 10 pontos. No último encontro foi realizado o jogo, para o qual não foi feita avaliação. A descrição da nota dos alunos em cada uma das quatro tarefas e da média geral dos alunos na atividade é apresentada na Tabela 1. Destaca-se que para a Tarefa 3 foi feita uma avalição em cada encontro (denotadas por 3 e 3R). O número de alunos variou entre as tarefas em razão de eventuais ausências nas aulas.

Tabela 1. Medidas descritivas das notas dos alunos por tarefa e da média geral.

\begin{tabular}{c|cccc|ccccc}
\hline Tarefa & $\mathrm{n}$ & Média & $\mathrm{DP}$ & $\mathrm{CV}(\%)$ & Mínimo & $\mathrm{Q} 1$ & $\mathrm{Md}$ & $\mathrm{Q} 3$ & Máximo \\
\hline 1 & 24 & 8,0 & 2,9 & 36,2 & 0,0 & 7,6 & 9,2 & 10,0 & 10,0 \\
2 & 24 & 8,6 & 1,7 & 20,1 & 4,2 & 7,6 & 9,2 & 10,0 & 10,0 \\
3 & 20 & 7,8 & 2,3 & 29,1 & 3,5 & 6,1 & 8,5 & 10,0 & 10,0 \\
$3 \mathrm{R}$ & 24 & 9,4 & 1,3 & 14,2 & 5,0 & 10,0 & 10,0 & 10,0 & 10,0 \\
4 & 25 & 8,0 & 2,9 & 22,0 & 4,0 & 10,0 & 10,0 & 10,0 & 10,0 \\
\hline Atividade & 26 & 8,6 & 1,7 & 18,1 & 2,7 & 7,9 & 8,6 & 9,7 & 10,0 \\
\hline \\
Nota: n \\
Md = mediana; Q3 3 alunos; DP = desvio padrão; CV = Coeficiente de variação; Q1 = primeiro quartil;
\end{tabular}

Nas avaliações individuais das tarefas, as notas da maioria dos alunos foram altas, com médias da turma variando entre 7,8 e 9,4 pontos. A variabilidade das notas em torno da média foi menor nas avaliações das tarefas 2, 3R e $4(C V=20 \%, 14 \%$ e $22 \%$, respectivamente). A média geral dos alunos na atividade foi 8,6 , evidenciando que a turma teve um bom desempenho. Apesar de alguns alunos apresentarem desempenho baixo na atividade, os quartis indicam que $75 \%$ da turma alcançou média maior ou igual a 7,9. A análise das notas por tarefa mostra que o desempenho dos alunos foi melhorando a cada tarefa. Na avaliação da tarefa 3R os alunos apresentaram as maiores notas (média: $9,4)$ com menor variação $(C V=14 \%)$. A média geral da turma na atividade foi 8,6 , com valores variando de 2, 7 a 10, 0 pontos. Os quartis indicam que, $50 \%$ dos alunos alcançaram média maior ou igual a 8,6 e 25\%, obtiveram média menor ou igual a 7, 9 . Portanto, o desempenho geral da turma na atividade foi satisfatório.

No primeiro dia de aula os alunos foram submetidos a um teste, composto por questões relacionadas às habilidades específicas desenvolvidas na atividade. Após a conclusão da atividade, no último encontro, o mesmo teste foi repetido. A finalidade da aplicação do teste em dois momentos (pré e pós) foi avaliar se houve efeito da atividade proposta sobre as habilidades dos alunos. A escala de pontuação do teste variou de 0 a 10 e a diferença entre as duas notas expressa o ganho (melhora) no desempenho do aluno. A pontuação no pré-teste descreve a condição inicial do aluno em relação àquelas habilidades específicas trabalhadas na atividade. As medidas descritivas das notas nos dois testes e do ganho dos alunos é apresentada na Tabela 2. Nesta descrição foram considerados 
somente os 22 alunos que realizaram os dois testes. Analisando as notas no pré-teste, observa-se que a turma alcançou média de 5,82 pontos, com coeficiente de variação (CV) de $33,2 \%$. No pós-teste a média aumentou para 7,04 pontos e o $\mathrm{CV}$ foi ligeiramente menor $(30,2 \%)$. O ganho médio positivo $(1,21$ pontos) indica que a turma melhorou seu desempenho geral no pós-teste, mas a variação dos ganhos foi elevada.

Tabela 2. Medidas descritivas das notas dos alunos, nos dois testes (pré e pós), e do ganho (diferença entre as duas notas).

\begin{tabular}{c|cccc|ccc}
\hline Teste & Número de alunos & Média & Desvio padrão & $\mathrm{CV}(\%)$ & Mínimo & Mediana & Máximo \\
\hline Pré & 22 & 5,82 & 1,93 & 33,20 & 2,7 & 6,6 & 9,4 \\
Pós & 22 & 7,04 & 2,13 & 30,22 & 4,2 & 7,6 & 9,6 \\
\hline Ganho & 22 & 1,21 & 1,88 & - & $-2,25$ & 0,89 & 5,67 \\
\hline
\end{tabular}

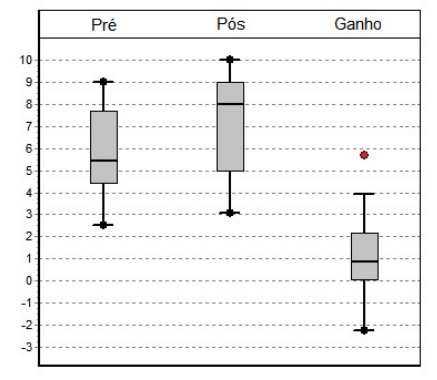

Figura 6. Distribuição das notas dos alunos nos testes (pré e pós) e da variável ganho.
Nos gráficos de caixa, apresentados na Figura 6, é possível verificar que as notas dos alunos nos dois testes possuem distribuições assimétricas. Esses gráficos evidenciam também que pelo menos $50 \%$ das notas estão entre 6,6 e 9,4 , no pré-teste, e entre 7,6 e 9,6, no pós-teste. Para a variável ganho observa-se a ocorrência de um valor atípico superior ( 5,67 - ponto vermelho no gráfico), embora os demais valores apresentem distribuição simétrica. Verifica-se que pelo menos $50 \%$ dos alunos tiveram ganho maior ou igual 0,89 pontos.

Também foi analisada a frequência das notas dos alunos nos dois testes em relação à nota 7,0 (sete), que, em geral, é considerada a nota mínima para a aprovação sem recuperação (Tabela 3). Verifica-se que houve uma inversão das frequências: no pré teste $36 \%$ dos alunos alcançaram nota maior ou igual a sete, enquanto que no pós-teste esse percentual aumentou para 59\%. A significância do efeito da atividade sobre as habilidades específicas dos alunos pode ser verificada por meio de um teste de hipótese. Para tal, utilizou-se o teste t para amostras pareadas, $\operatorname{com} \alpha=0,05$, cujos resultados são apresentados na Tabela 4. A hipótese sob verificação no teste $\left(H_{0}\right)$ supõe que o ganho médio $(\mu)$ dos alunos não difere de zero, ou seja, $H_{0}: \mu=0$. Na prática essa hipótese significa que a atividade não melhora o desempenho dos alunos no pós-teste.

Tabela 3. Distribuição de frequência (absoluta e percentual) dos alunos segundo suas notas nos testes realizados antes e depois da atividade.

\begin{tabular}{c|cc}
\hline Nota & Pré & Pós \\
\hline$<7$ & $14(64 \%)$ & $9(41 \%)$ \\
$\geq 7$ & $8(36 \%)$ & $13(59 \%)$ \\
\hline Total & 22 & 22 \\
\hline
\end{tabular}

O teste revela a rejeição da hipótese $H_{0}$ (valor $p<0,05$ ), significando que a atividade promoveu melhora significativa nas habilidades específicas abordadas na atividade.

\section{Considerações Finais}

Esse artigo teve como objetivo apresentar uma metodologia de aplicação de um jogo educacional de RPG. O jogo teve propósito de desenvolver habilidades do PC integradas a 
Tabela 4. Resultados do teste de significância para a variável ganho.

\begin{tabular}{cccccc}
\hline Ganho médio & Hipótese & Estatística T & Valor $\mathrm{p}$ & $\alpha$ & Decisão \\
\hline 1,22 & $\mu=0$ & 3,03 & 0,0064 & 0,05 & Rejeita \\
\hline
\end{tabular}

prática dos fundamentos da aritmética elementar. Por meio de um estudo de caso, foi observado a interação das crianças com o jogo, sendo possível perceber, através dos resultados, uma melhora nas habilidades avaliadas. A abordagem adotada foi atrativa aos alunos do ensino fundamental, mostrando que é possível aprender por meio de jogos do gênero RPG. Como trabalhos futuros, pretende-se elaborar novas propostas de atividades que promovam diversas competências do PC e aplicá-las em sala de aula.

\section{Referências}

Bartz, M. S. (2018). Uma proposta de atividade desplugada baseada em um jogo RPG para promover o pensamento computacional e avaliar a colaboração entre estudantes do ensino fundamental. TCC (Ciência da Computação), UFPEL.

Bell, T., Witten, I. H., and Fellows, M. (1999). Computer Science Unplugged: Off-Line Activities and Games for All Ages. Disponível em: http: / csunplugged.org.

Cao, F., Ding, D., and Zhu, M. (2019). Introducing Fundamental Computer Science Concepts through Game Design. J. Comput. Sci. Coll., 34(4):90-96.

Clarke, S. et al. (2016). EscapED: Adapting Live-Action, Interactive Games to Support Higher Education Teaching and Learning Practices. Springer International Publishing.

Costa, S. S. et al. (2015). Um estudo exploratório dos games para introdução ao pensamento computacional. In Conahpa, pages 1-15.

Csizmadia, A. et al. (2015). Computational thinking - a guide for teachers. Disponível em: https://www. computingatschool.org.uk/computationalthinking. Acesso em: 28-02-2021.

da Silva, B. C. et al. (2014). Jogos digitais educacionais como instrumento didático no processo de ensino-aprendiz. das op. básicas de matemática. In SBIE, pages 682-691.

Grando, A. and Tarouco, L. (2008). O uso de jogos educacionais do tipo RPG na educação. RENOTE, 6(1):1-10.

Gygax, G. and Arneson, D. (1974). Wargames Campaigns Playable With Paper and Pencil and Miniature Figures. Tactical Studies Rules.

Junior, B., Cavalheiro, S., and Foss, L. (2018). Uma análise de um jogo educacional sob a ótica do pensamento computacional. In SBIE, pages 595-604.

MEC (2018). Base Nacional Comum Curricular. Disponível em: http:// basenacionalcomum.mec.gov.br/abase. Acesso em: 31-03-2021.

Melo, D. et al. (2018). Robô Euroi: Game de estratégia matemática para exercitar o pensamento computacional. In SBIE, pages 685-694.

Pires, F. et al. (2018). O livro do conhecimento: Um jogo de aventura para exercitar a ortografia. In SBIE, pages 695-704.

Ribeiro, L., Foss, L., and da Costa Cavalheiro, S. A. (2017). Entendendo o pensamento computacional. Disponível em: https://arxiv.org/abs/1707.00338. 